\title{
TRATAMENTO FUNGICIDA E PELICULIZAÇ̃̃o DE SEMENTES DE SOJA SUBMETIDAS AO ARMAZENAMENTO
}

\author{
Fungicide treatment and film coating of soybean seeds submitted to storage
}

\author{
Carlos Eduardo Pereira ${ }^{1}$, João Almir Oliveira ${ }^{2}$, Renato Mendes Guimarães ${ }^{2}$, \\ Antônio Rodrigues Vieira ${ }^{3}$, José Renato Emilioreli Evangelista ${ }^{2}$, Gustavo Evangelista Oliveira ${ }^{4}$
}

\begin{abstract}
RESUMO
O tratamento de sementes de soja com fungicidas vem sendo utilizado como importante ferramenta no controle de patógenos. Nesse trabalho, objetivou-se estudar o desempenho de sementes de soja tratadas com fungicidas e peliculizadas, antes e após o armazenamento. Foram utilizados cinco lotes de sementes, cultivar Monsoy 6101, submetidos aos tratamentos: thiabendazole+thiram sem polímero, carbendazin+thiram sem polímero, sem fungicida (testemunha) sem polímero, além desses tratamentos realizados via peliculização (com polímero). A qualidade fisiológica e sanitária das sementes foi avaliada inicialmente e após seis meses de armazenamento em condições ambientais, pelas seguintes determinações: teor de água, teste de germinação, emergência em bandeja, teste de frio e de sanidade. Conclui-se que a peliculização, em associação com fungicidas, não afeta a qualidade fisiológica das sementes de soja e o tratamento de lotes de sementes de soja com os fungicidas thiabendazole+thiram e carbendazin+thiram melhora seu desempenho e qualidade sanitária.
\end{abstract}

Termos para indexação:Glycine max, thiabendazole, thiram, carbendazin, polímeros.

\section{ABSTRACT}

The treatment of soybean seeds by fungicides has been used as an important tool in pathogen control. The objective of this work was to verify the performance of soybean seeds treated with fungicide and film coating, prior and after storage. Five seed lots, cultivar Monsoy 6101, were treated with thiabendazole+thiram without polymer, carbendazin+thiram without polymer, without fungicide (control), without polymer, and treatments by film coating (with polymer). The physiological and sanitary quality of the seeds was evaluated initially and after six months storage, under environmental conditions, according to the following characteristics: water content, test of germination and emergence on tray, blotter test and cold test. The film coating associated with fungicides does not affect the physiological quality of soybean seeds and the soybean seed treatment with the fungicides thiabendazole+thiram and carbendazin+thiram improves performance and sanitary quality.

Index terms: Glycine max, thiabendazole, carbendazin, thiram, polymers.

(Recebido em 17 de março de 2009 e aprovado em 23 de abril de 2010)

\section{INTRODUÇÃO}

A qualidade das sementes é fator primordial para estabelecimento de lavouras com alto potencial produtivo. No entanto, condições climáticas adversas podem comprometer o desenvolvimento inicial da cultura. Assim, em situações desfavoráveis à germinação e emergência, principalmente baixa disponibilidade de água no solo, o tratamento de sementes de soja com fungicidas é uma prática essencial para assegurar estande adequado, além de reduzir a possibilidade de introdução de patógenos em áreas indenes.

Sementes de soja tratadas podem mostrar respostas diferenciadas em função do fungicida utilizado (Goulart et al., 2000). Efeitos positivos na germinação e emergência em campo têm sido observados (Gianasi et al., 2000), entretanto, determinados produtos com ação fungicida podem exercer efeito tóxico sobre as sementes de soja (Gianasi et al., 2000), ou mesmo não interferir na germinação e vigor (Pereira et al., 2009). Também, a eficiência do tratamento para controle dos patógenos nas sementes de soja depende dos fungicidas aplicados (Goulart et al., 2000).

Com relação ao armazenamento de sementes tratadas, Moraes et al. (2001) constataram que sementes tratadas com carboxin+thiram, 180 dias antes da semeadura, não tiveram alteração da qualidade fisiológica. Marcos Filho e Souza (1983) verificaram que sementes de soja tratadas com fungicidas (thiram e tiofanato metílico+thiram) antes do armazenamento foram beneficiadas quanto ao vigor, mas que os resultados obtidos em seu trabalho não foram suficientes para esclarecer os efeitos do tratamento antecipado nas sementes de soja.

\footnotetext{
1Universidade Federal do Amazonas/UFAM - Instituto de Educação Agricultura e Ambiente/IEAA - 69800-000 - Humaitá, AM - ce-pereira@bol.com.br 2Universidade Federal de Lavras/UFLA - Departamento de Agricultura/DAG - Lavras, MG

${ }^{3}$ Empresa de Pesquisa Agropecuária de Minas Gerais/EPAMIG - Lavras, MG

${ }^{4}$ Universidade Federal de Lavras/UFLA - Lavras, MG
}

Ciênc. agrotec., Lavras, v. 35, n. 1, p. 158-164, jan./fev., 2011 
Atualmente, a crescente preocupação com o meio ambiente e com a segurança durante a manipulação de sementes tratadas tem aumentado a demanda por tecnologias de aplicação que permitam a redução dos riscos, sem que a qualidade das sementes seja comprometida. Nesse sentido, a peliculização pode ser empregada, por se observar uma melhor retenção dos produtos fitossanitários às sementes (Sampaio \& Sampaio, 1998; Silveira, 1998), garantindo que estes atuem onde são necessários. Entretanto, tem-se observado que as consequências do tratamento fungicida associado à peliculização dependem da qualidade das sementes a serem tratadas (Lima et al., 2006).

Assim, em razão pequeno volume de informações e pesquisas conclusivas relacionadas à peliculização de sementes, objetivou-se, nesse trabalho estudar o desempenho de sementes de soja tratadas com fungicidas e peliculizadas, antes e após o armazenamento.

\section{MATERIAL E MÉTODOS}

Foram avaliadas sementes de cinco lotes, cultivar Monsoy 6101, submetidas aos tratamentos: thiabendazole+thiram $\left(\right.$ Tegran $\left.^{\circledR}\right)$ sem polímero, carbendazin+thiram (Derosal Plus ${ }^{\circledR}$ ) sem polímero, sem fungicida (testemunha) sem polímero, thiabendazole+thiram com polímero, carbendazin+thiram com polímero, sem fungicida com polímero. Tanto os fungicidas como o polímero (Disco Agroblue 201) foram aplicados na dosagem de $200 \mathrm{~mL}$ por $100 \mathrm{~kg}$ de sementes.

Após tratadas e acondicionadas em embalagens de papel multifoliado, as sementes foram armazenadas por seis meses sob condições ambientais (temperatura e umidade relativa do ar média de $22,3^{\circ} \mathrm{C}$ e $63 \%$, respectivamente). Posteriormente, procedeu-se a avaliação das sementes por meio de: teor de água (determinado pelo método da estufa a $105^{\circ} \mathrm{C}$, por 24 horas (Brasil, 1992), sendo utilizadas duas repetições de $50 \mathrm{~g}$ de sementes, por tratamento); teste de germinação (foram avaliadas 200 sementes por tratamento, divididas em quatro repetições com 50 sementes, em rolo de papel. Após, as sementes foram mantidas durante cinco dias em germinador à $25^{\circ} \mathrm{C}$ e, em seguida, avaliadas de acordo com as Regras para Análise de Sementes (Brasil, 1992) sendo os resultados expressos em porcentagem de plântulas normais); emergência em bandeja e índice de velocidade de emergência (IVE) (a semeadura foi realizada em bandejas plásticas contendo substrato areia + solo na proporção de 2:1. Foram utilizadas quatro repetições com 50 sementes por tratamento. Após a semeadura, as bandejas foram mantidas durante 14 dias em câmara de crescimento vegetal à $25^{\circ} \mathrm{C}$ com fotoperíodo de 12 horas. Os resultados foram expressos em porcentagem de plântulas normais emergidas aos 14 dias. Foram realizadas avaliações diárias a partir da emergência da primeira plântula, anotando-se o número de plântulas emergidas até a estabilização, para determinação do IVE, segundo fórmula proposta por Maguire (1962); teste de frio (a semeadura de quatro repetições de 50 sementes por tratamento foi realizada em bandejas plásticas, contendo substrato areia + solo na proporção de $2: 1$, com umidade ajustada para $70 \%$ da capacidade de retenção de água, conforme prescrições da International Seed Test Association - ISTA (1995). Após a semeadura, as bandejas foram dispostas em câmara fria a $10^{\circ} \mathrm{C}$, durante sete dias sendo posteriormente transferidas para câmara de crescimento vegetal à $25^{\circ} \mathrm{C}$ com fotoperíodo de 12 horas por sete dias, quando se procedeu a avaliação. Os resultados foram expressos em número de plântulas normais emergidas); sanidade das sementes (foi empregada a técnica de incubação em placas de Petri de $15 \mathrm{~cm}$ contendo três folhas de papel de filtro umedecidos em solução de 2,4 diclorofenoxiacetato de potássio (2,4-D) a 5 ppm. Foram utilizadas 25 sementes por tratamento por placa, num total de oito repetições. A incubação foi à temperatura de $20^{\circ} \mathrm{C}$ e fotoperíodo de 12 horas por sete dias, quando foram identificados os patógenos presentes).

Foi utilizado o delineamento fatorial $5 \times 3 \times 2$ (fatores: lotes, fungicidas e polímero) em sistema inteiramente casualizado. Os dados obtidos para teste de germinação, de frio e emergência em bandeja foram transformados para

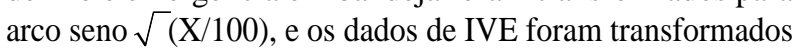
em $\sqrt{(} \mathrm{X}+0,5)$, antes da análise de variância, sendo os dados analisados empregando-se o pacote computacional SISVAR. Para a sanidade das sementes não foram empregadas ferramentas estatísticas.

\section{RESULTADOS E DISCUSSÃO}

\section{Avaliação da qualidade das sementes antes do armazenamento}

Verificou-se que o teor de água das sementes, oscilando entre 8,34 e $9,68 \%$, não foi influenciado pela aplicação dos fungicidas e polímero, em razão do pequeno volume dos produtos utilizados e ao restabelecimento do equilíbrio higroscópico das sementes com a umidade relativa do ar

Por meio do teste de germinação, verificou-se que, em geral, os tratamentos com thiabendazole+thiram ou carbendazin+thiram tiveram porcentagem de germinação significativamente superior às sementes não tratadas (Tabela 1). Aumentos na porcentagem de germinação de 
sementes de soja e emergência em campo, em resposta à aplicação de fungicidas, também foram observados por Gianasi et al. (2000), provavelmente pela inibição do crescimento e desenvolvimento dos principais patógenos associados a essas sementes.

Não foram observadas diferenças entre sementes submetidas ou não a peliculização, em geral (Tabela 1). O revestimento não afetou a germinação, bem como a ação dos fungicidas. Resultados semelhantes foram obtidos por Pereira et al. (2007), os quais constataram que o filme utilizado para o revestimento das sementes de soja não afeta a eficiência do tratamento fungicida. De forma semelhante, não foram verificados efeitos significativos da peliculização sobre a germinação e o vigor de sementes de soja (Pereira et al., 2007), algodão (Lima et al., 2006) e milho (Rivas et al., 1998).

Pelos resultados do teste de emergência em bandeja, verifica-se que, para as sementes tratadas com carbendazin+thiram ou thiabendazole+thiram, a porcentagem de plântulas normais emergidas foi significativamente maior que nas não tratadas, não diferenciando entre si (Tabela 1). A porcentagem de emergência para as sementes tratadas foi em média acrescida de 44,3\%, em relação às sementes não tratadas, confirmando a importância do tratamento fungicida mesmo quando as condições de germinação e emergência são ideais, porém há ocorrência de patógenos associados às sementes. Esses resultados corroboram aqueles obtidos por Goulart \& Melo Filho (2000), os quais também verificaram aumento no vigor das sementes de soja tratadas com os fungicidas thiram, benomil, thiabendazole e com as misturas carboxim+thiram, carbendazim+thiram, iprodione+thiram, thiram+captan, carbendazin+thiram e thiabendazole + thiram. Nesse sentido, o tratamento fungicida de sementes de soja tem sido recomendado para o controle de fungos associados às sementes, visando a melhorar seu desempenho germinativo (Machado, 2000).

Da mesma forma, como observado para o teste de germinação, em geral não houve efeitos significativos da peliculização sobre a porcentagem de emergência de plântulas, confirmando que a aplicação dos polímeros não afetou a qualidade das sementes.

Obsevou-se, ainda, que o índice de velocidade de emergência das sementes tratadas com carbendazin+thiram $($ IVE $=11,33 \mathrm{a})$ ou thiabendazole+thiram $(\operatorname{IVE}=11,35 \mathrm{a})$ foi significativamente maior o das sementes não tratadas (IVE = 9,36 b), do mesmo modo como observado para os testes de germinação e emergência. Em razão da deterioração das sementes ocasionada por patógenos, muitas vezes as sementes contaminadas ou infectadas por esses microrganismos têm um desempenho inferior (Machado, 2000) e, nesse sentido, o tratamento fungicida destas sementes pode melhorar seu desempenho.

Tabela 1 - Porcentagem média de germinação de sementes $(\mathrm{CV}=13,5 \%)$ e de emergência de plântulas $(\mathrm{CV}=7,9 \%)$ de soja tratadas com fungicidas $(\mathrm{S}=$ sem fungicida; $\mathrm{C}+\mathrm{T}=$ Carbendazin e Thiram; $\mathrm{T}+\mathrm{T}=$ Thiabendazole e Thiram) e peliculizadas, antes do armazenamento.

\begin{tabular}{|c|c|c|c|c|c|c|c|}
\hline \multirow{3}{*}{ Lotes } & \multirow{3}{*}{ Polímero } & \multicolumn{3}{|c|}{ Porcentagem de Germinação } & \multicolumn{3}{|c|}{ Porcentagem de Emergência } \\
\hline & & \multicolumn{3}{|c|}{ Fungicidas } & \multicolumn{3}{|c|}{ Fungicidas } \\
\hline & & $S$ & $\mathrm{C}+\mathrm{T}$ & $\mathrm{T}+\mathrm{T}$ & $\mathrm{S}$ & $\mathrm{C}+\mathrm{T}$ & $\mathrm{T}+\mathrm{T}$ \\
\hline \multirow{2}{*}{ L1 } & Com & 92 a A & 92 a A & 93 a A & 62 a B & 92 a A & 86 a $\mathrm{A}$ \\
\hline & Sem & $79 \mathrm{~b} \mathrm{C}$ & 89 a B & 96 a $\mathrm{A}$ & 55 a B & 89 a $\mathrm{A}$ & 90 a $\mathrm{A}$ \\
\hline \multirow{2}{*}{$\mathrm{L} 2$} & Com & $79 \mathrm{~b} \mathrm{~B}$ & 89 a $\mathrm{A}$ & 92 a $A$ & 72 a B & 93 a $\mathrm{A}$ & 93 a $\mathrm{A}$ \\
\hline & Sem & 87 a B & 92 a $\mathrm{AB}$ & 93 a A & 69 a B & 96 a A & 95 a A \\
\hline \multirow{2}{*}{ L3 } & Com & 75 a B & 92 a $\mathrm{A}$ & 95 a $\mathrm{A}$ & 60 a B & 92 a $\mathrm{A}$ & 90 a $\mathrm{A}$ \\
\hline & Sem & 72 a B & 89 a $\mathrm{A}$ & 92 a A & 69 a B & 86 a A & 90 a A \\
\hline \multirow{2}{*}{ L4 } & Com & 70 a B & 91 a $\mathrm{A}$ & 87 a A & $52 \mathrm{~b} \mathrm{~B}$ & 92 a A & 90 a $\mathrm{A}$ \\
\hline & Sem & 75 a B & 86 a A & 92 a A & 67 a B & 86 a A & 94 a A \\
\hline \multirow{2}{*}{ L5 } & Com & 75 a B & 92 a A & $86 \mathrm{~b} \mathrm{~A}$ & 69 a B & 90 a A & 90 a A \\
\hline & Sem & 79 a B & 86 a B & 94 a A & $55 \mathrm{~b} \mathrm{~B}$ & 92 a A & 92 a A \\
\hline
\end{tabular}

Médias seguidas pela mesma letra maiúscula na linha e minúscula na coluna, dentro de cada lote de sementes, não diferem estatisticamente entre si, pelo Teste de Tukey e de F, respectivamente, a 5\% de probabilidade. 
Pelos resultados do teste de frio, os lotes de sementes diferiram significativamente entre si, quando as sementes não foram tratadas com fungicida (Tabela 2). A maior porcentagem de emergência foi observada para as sementes do lote L5, enquanto para as sementes dos lotes L2 e L4 a média de emergência foi menor. Quando as sementes foram tratadas com o fungicida thiabendazole+thiram, ocorreram os maiores valores de emergência.

\section{Avaliação da qualidade das sementes após seis meses de armazenamento}

Após o armazenamento, as sementes tiveram teor de água entre $9,29 \%$ e $10,21 \%$, sendo em média cerca de $1 \%$ acima do teor de água antes do armazenamento. Esse aumento deve-se à maior umidade relativa do ar ao final do período de armazenamento e, consequente aumento no teor de água das sementes para restabelecer o equilíbrio higroscópico. Entretanto, não foram observadas relações da variação no teor de água das sementes com os tratamentos químicos realizados.

Maior porcentagem de germinação foi observada para sementes peliculizadas e tratadas com fungicida thiabendazole+thiram (Tabela 3). No entanto, para sementes sem revestimento não foram observadas diferenças significativas entre tratamentos fungicidas. Observou-se, ainda, maior porcentagem de germinação das sementes peliculizadas em relação as não peliculizadas, quando não foi realizado o tratamento fungicida. Também, Bays et al. (2007) verificaram que sementes que receberam somente o polímero no material de recobrimento se comportaram positivamente em condições de campo, mostrando um possível efeito fungicida na composição química do produto de revestimento.

Mesmo observando-se variações significativas na porcentagem de germinação, em todos os tratamentos a

Tabela 2 - Resultados médios do teste de frio $(\mathrm{CV}=13,5 \%)$ de sementes de diferentes lotes de sementes de soja tratadas com fungicidas, antes do armazenamento.

\begin{tabular}{cccc}
\hline \multirow{2}{*}{ Lotes } & \multicolumn{3}{c}{ Fungicidas } \\
\cline { 2 - 4 } & Sem & Carbendazin+Thiram & Thiabendazole+Thiram \\
\hline L1 & $48 \mathrm{ab} \mathrm{B}$ & $43 \mathrm{a} \mathrm{B}$ & $60 \mathrm{a} \mathrm{A}$ \\
L2 & $36 \mathrm{~b} \mathrm{~B}$ & $48 \mathrm{a} \mathrm{AB}$ & $50 \mathrm{a} \mathrm{A}$ \\
L3 & $47 \mathrm{ab} \mathrm{A}$ & $48 \mathrm{a} \mathrm{A}$ & $48 \mathrm{a} \mathrm{A}$ \\
L4 & $38 \mathrm{~b} \mathrm{~B}$ & $36 \mathrm{a} \mathrm{B}$ & $54 \mathrm{a} A$ \\
L5 & $54 \mathrm{a} \mathrm{A}$ & $48 \mathrm{a} \mathrm{A}$ & $57 \mathrm{a} \mathrm{A}$ \\
\hline
\end{tabular}

Médias seguidas pela mesma letra maiúscula na linha e minúscula na coluna não diferem estatisticamente entre si, pelo Teste de Tukey, respectivamente, a $5 \%$ de probabilidade.

Tabela 3 - Germinação (CV = 4,6\%) de sementes de soja $(\%)$ de diferentes lotes, tratadas com fungicidas e peliculizadas, avaliadas após seis meses de armazenamento.

\begin{tabular}{llcc}
\hline \multirow{2}{*}{ Fatores/Tratamentos } & \multicolumn{2}{c}{ Polímero } \\
\cline { 3 - 4 } Fungicidas & Sem & Com & Sem \\
\cline { 2 - 4 } & Carbendazin+Thiram & $84 \mathrm{~b} \mathrm{~B}$ & 87 a A \\
& Thiabendazole+Thiram & $86 \mathrm{~b} \mathrm{~A}$ & 87 a B \\
\hline \multirow{6}{*}{ Lotes } & L1 & 89 a A & 87 a B \\
& L2 & 91 a A & 89 a A \\
& L3 & 91 a A & 88 a A \\
& L4 & 84 cb B & 81 b A \\
\hline
\end{tabular}

Médias seguidas pela mesma letra maiúscula na linha e minúscula na coluna, dentro dos fatores fungicidas e lotes, não diferem estatisticamente entre si, pelo Teste de F e de Tukey, respectivamente, a 5\% de probabilidade. 
germinação, após o armazenamento foi superior ao padrão nacional de comercialização de $80 \%$ (Brasil, 2008).

A porcentagem de germinação das sementes, com e sem polímero, foram semelhantes entre si na maioria dos lotes, no entanto, observa-se que o efeito da peliculização depende do lote de semente (Tabela 3), corroborando trabalho realizado por Trentini (2004), onde verificaram-se respostas diferenciadas dos lotes avaliados em relação à peliculização.

Após o armazenamento, não foram observadas diferenças de germinação superiores a 5\%, diferentemente das sementes antes do período de armazenamento. Possivelmente, isto tenha ocorrido em função de uma redução na incidência Phomopsis e Fusarium nas sementes não tratadas ao longo do armazenamento (Tabela 4).

Goulart \& Cassetari Neto (1987) verificou que sementes de soja armazenadas tiveram o índice de infecção por Phomopsis sp. reduzido. Pereira et al. (2007), trabalhando com sementes de soja armazenadas, concluiu que os fungos de campo associados às sementes diminuíram durante o armazenamento das sementes, enquanto que os fungos de armazenamento aumentaram. Observa-se, da mesma forma, como constado por esse autor, um aumento do fungo Aspergillus para alguns lotes, principalmente nas sementes não peliculizadas.

No teste de frio, as sementes tratadas com thiabendazole+thiram (67\% a) e carbendazin+thiran $(60 \%$ b) tiveram, significativamente, maiores percentuais de emergência que as sementes não tratadas $(36 \%$ c). Assim como observado para as sementes avaliadas antes do armazenamento por meio desse mesmo teste, as sementes tratadas com thiabendazole+thiram tiveram porcentagem de emergência significativamente maior que as sementes tratadas com carbendazin+thiram.

Nas condições do teste de frio a baixa temperatura dificulta a reorganização de membranas celulares durante o período de embebição e, consequentemente, torna a germinação mais lenta (Burris \& Navratil, 1979), aumentando a suscetibilidade das sementes à infecção por patógenos. Nesse sentido, a maior porcentagem de emergência das sementes tratadas com fungicidas devese, provavelmente, a proteção das sementes conferida por esses produtos. Assim, segundo Zorato \& Henning (2001), o tratamento de sementes com fungicidas é importante por controlar patógenos associados a sementes e assegurar um estande adequado quando as condições de clima e solo são desfavoráveis.

Tabela 4 - Incidência de Colletotrichum truncatum, Fusarium spp., Cercospora kikuchii, Phomopsis e Aspergillus (\%) em cinco lotes de sementes de soja, não tratados e submetidos ou não a peliculização, avaliações antes e após o armazenamento.

\begin{tabular}{|c|c|c|c|c|c|c|c|c|c|c|}
\hline \multirow{3}{*}{ Patógenos } & \multicolumn{10}{|c|}{ Polímero/Lotes } \\
\hline & \multicolumn{5}{|c|}{ Com } & \multicolumn{5}{|c|}{ Sem } \\
\hline & L1 & L2 & L3 & $\mathrm{L} 4$ & L5 & L1 & L2 & L3 & L4 & L5 \\
\hline & \multicolumn{10}{|c|}{ Avaliação antes do armazenamento } \\
\hline C. truncatum & 0,00 & 0,00 & 0,00 & 0,00 & 0,00 & 0,00 & 0,00 & 0,00 & 0,52 & 0,00 \\
\hline Fusarium spp. & 2,52 & 22,00 & 19,52 & 8,00 & 12,00 & 6,00 & 15,52 & 19,52 & 19,00 & 11,52 \\
\hline C. kikuchii & 0,00 & 4,52 & 5,52 & 2,00 & 1,52 & 0,00 & 2,00 & 1,52 & 4,52 & 3,52 \\
\hline Phomopsis & 21,52 & 13,00 & 23,12 & 18,52 & 17,00 & 16,00 & 15,00 & 17,00 & 20,52 & 18,52 \\
\hline \multirow[t]{2}{*}{ Aspergillus } & 0,00 & 1,52 & 0,00 & 0,00 & 0,52 & 0,00 & 0,52 & 0,00 & 0,00 & 1,00 \\
\hline & \multicolumn{10}{|c|}{ Avaliação após o armazenamento } \\
\hline C. truncatum & 0,00 & 0,00 & 0,52 & 0,00 & 0,52 & 0,00 & 0,00 & 1,52 & 0,00 & 1,00 \\
\hline Fusarium spp. & 6,52 & 3,00 & 8,00 & 5,52 & 6,52 & 6,52 & 4,52 & 5,00 & 9,52 & 9,00 \\
\hline C. kikuchii & 1,00 & 1,00 & 0,52 & 4,00 & 0,00 & 0,52 & 1,00 & 5,52 & 4,52 & 4,00 \\
\hline Phomopsis & 1,00 & 6,00 & 6,00 & 7,00 & 3,52 & 3,00 & 3,52 & 4,00 & 4,00 & 5,52 \\
\hline Aspergillus & 1,00 & 0,00 & 0,00 & 2,52 & 0,52 & 0,52 & 0,00 & 2,00 & 4,00 & 0,00 \\
\hline
\end{tabular}




\section{CONCLUSÕES}

A peliculização em associação com fungicidas não afeta a qualidade fisiológica das sementes de soja.

O tratamento de lotes de sementes de soja com os fungicidas thiabendazole+thiram e carbendazin+thiram melhoram seu desempenho e qualidade sanitária.

\section{AGRADECIMENTOS}

À Fundação de Apoio à Pesquisa do Estado de Minas Gerais - FAPEMIG, pelo financiamento da pesquisa.

\section{REFERÊNCIAS BIBLIOGRÁFICAS}

BAYS, R.; BAUDET, L.; HENNING, A.A.; LUCCA FILHO, O. Recobrimento de sementes de soja com micronutrientes, fungicida e polímero. Revista Brasileira de Sementes, Pelotas, v.29, n.2, p.60-67, ago. 2007.

BURRIS, J.S.; NAVRATIL, R.J. Relationship between laboratory cold test methods and field emergency in maize inbreds. Agronomy Journal, Madison, v.71, n.6, p.985-988, 1979.

BRASIL. Ministério da Agricultura e Reforma Agrária. Regras para análise de sementes. Brasília: SNDA/ DNDV/CLAV, 1992. 365p.

BRASIL. Ministério da Agricultura, Pecuária e Abastecimento. Sistemas em produção. Brasília, 2008. Disponível em: <http:// extranet.agricultura.gov.br/sislegis-consultah iservlet/VizualizarAnexo? id=10828ㄱ. Acesso em: 15 abr. 2008 .

GIANASI, L.; FILHO, A.B.; FERNANDES, N.; LOURENÇO, S.A.; SILVA, C.L. Eficiência do fungicida captan associado a outros fungicidas no tratamento químico de sementes de soja. Summa

Phytopatologica, Jaboticabal, v.26, n.2, p.241-245, 2000.

GOULART, A.C.P.; ANDRADE, P.J.M.; BORGES, E.P. Controle de patógenos de soja pelo tratamento com fungicidas e efeitos na emergência e no rendimento de grãos. Summa Phytopathologica, Jaboticabal, v.26, n.3, p.341-346, 2000.

GOULART, A.C.P.; CASSETARI NETO, D. Efeito do ambiente de armazenamento e tratamento químico na germinação, vigor e sanidade de sementes de soja Glycine max (L.) Merrill, com alto índice de Phomopsis sp. Revista Brasileira de Sementes, Brasília, v.9, n.3, p.91-102, 1987.

GOULART, A.C.P.; MELO FILHO, G.A. de. Quanto custa tratar as sementes de soja, milho e algodão com fungicidas? Dourados: Embrapa/ CPAO, 2000. 23p. (Embrapa/CNPSo. Documentos, 11).

\section{INTERNATIONAL SEED TEST ASSOCIATION.}

Handbook of vigour test methods. 3.ed. Zurich: ISTA, 1995. $117 \mathrm{p}$.

LIMA, L.B.; SILVA, P.A.; GUIMARÃES, R.M.; OLIVEIRA, J.A. Peliculização e tratamento químico de sementes de algodoeiro (Gossypium hirsutum L.).

Ciência e Agrotecnologia, Lavras, v.30, n.6, p.1091-1098, nov./dez. 2006.

MACHADO, J.C. Tratamento de sementes no controle de doenças. Lavras: LAPS/UFLA/FAEPE, 2000. 138p.

MAGUIRE, J.D. Speed of germination aid in selection and evaluation for seedling and vigour. Crop Science, Madison, v.2, n.2, p.176-177, 1962.

MARCOS FILHO, J.; SOUZA, F.H.D. Conservação de sementes de soja tratadas com fungicidas. Anais da Escola Superior de Agricultura Luiz de Queiroz, Piracicaba, v.40, n.1, p.613, 1983.

MORAES, M.H.D.; MARUOKA, A.E.; GRAVENA, C.; MENTEN, J.O.M.; DIAS, P.M.F. Avaliação da eficiência do tratamento antecipado de sementes de soja com carboxin +thiram. Fitopatologia Brasileira, Brasília, v.26, p.426, 2001. Suplemento.

PEREIRA, C.E.; OLIVEIRA, J.A.; EVANGELISTA, J.R.E.; BOTELHO, F.J.E.; OLIVEIRA, G.E.; TRENTINI, P. Desempenho de sementes de soja tratadas com fungicidas e peliculizadas durante o armazenamento. Ciência e Agrotecnologia, Lavras, v.31, n.3, p.656-665, maio/jun. 2007.

PEREIRA, C.E.; OLIVEIRA, J.A.; OLIVEIRA, G.E.; ROSA, M.C.M.; COSTA NETO, J. Tratamento fungicida via peliculização e inoculação de Bradyrhizobium em sementes de soja. Revista Ciência Agronômica, Fortaleza, v.40, n.3, p.433-440, jul./set. 2009. 
RIVAS, B.A.; McGEE, D.C.; BURRIS, J.S. Tratamiento de semillas de maiz con polimeros para el control de Pythium spp. Fitopatologia Venezuelana, Caracas, v.11, n.1, p.10-15, 1998.

SAMPAIO, N.V.; SAMPAIO, T.G. Sementes: com as cores da eficiência. A granja do Ano, Porto Alegre, v.12, p.16-18, 1998.
SILVEIRA, S. Recobertura como medida para proteção da semente. Seed News, Pelotas, n.5, p.34-35, 1998.

ZORATO, M.; HENNING, A. Influência de tratamentos fungicidas antecipados, aplicados em diferentes épocas de armazenamento, sobre a qualidade de sementes de soja. Revista Brasileira de Sementes. Londrina, v.23, n.2, p.236-244, 2001. 